\title{
Prostatic Urethra Urothelial Carcinoma
}

National Cancer Institute

\section{Source}

National Cancer Institute. Prostatic Urethra Urothelial Carcinoma. NCI Thesaurus. Code C39900.

An urothelial carcinoma that arises from the urothelial lining of the prostatic urethra. 